\title{
Working
}

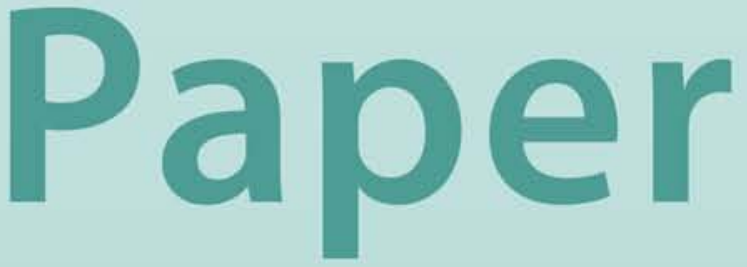


Threshold Effects in the Relationship Between Inflation and Growth

Mohsin S. Khan and Abdelhak S. Senhadji 


\title{
IMF Working Paper
}

\author{
IMF Institute
}

\section{Threshold Effects in the Relationship Between Inflation and Growth}

\author{
Prepared by Mohsin S. Khan and Abdelhak S. Senhadji ${ }^{1}$
}

June 2000

\begin{abstract}
The views expressed in this Working Paper are thosc of the author(s) and do not necessarily represent those of the IMF or IMF policy. Working Papers describe rescarch in progress by the author(s) and are published to elicit comments and to further debate.
\end{abstract}

This paper reexamines the issue of the existence of threshold effects in the relationship between inflation and growth, using new econometric techniques that provide appropriate procedures for estimation and inference. The threshold level of inflation above which inflation significantly slows growth is estimated at 1-3 percent for industrial countries and 7-11 percent for developing countries. The negative and significant relationship between inflation and growth, for inflation rates above the threshold level, is quite robust with respect to the estimation method, perturbations in the location of the threshold level, the exclusion of high-inflation observations, data frequency, and alternative specifications.

JEL Classification Numbers:E31; O40

Keywords: Inflation; Growth; Threshold Effects

Author's E-Mail Address:mkhan@imf.org and asenhadji@imf.org

${ }^{1}$ The authors are particularly grateful to Bruce Hansen for very helpful discussions and advice on the econometric issues. They also thank Paul Cashin, Stanley Fischer, John McDermott, Peter Montiel, Ratna Sahay, and a number of colleagues in the IMF Institute for extremely useful comments. 
Contents

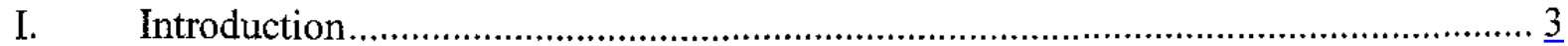

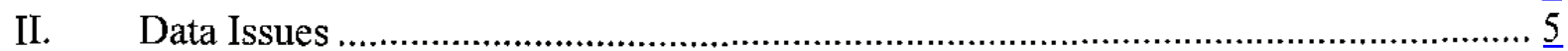

III. Model Specification and Estimation.............................................................. $\underline{6}$

IV. Estimation and Inference Results.................................................................. $\frac{8}{8}$

A. Test for Existence of Threshold Effects................................................... $\underline{8}$

B. Estimation Results .............................................................................

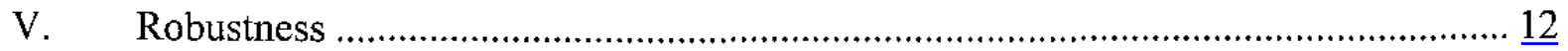

A. Sensitivity to the Estimation Method................................................. $\frac{12}{13}$

B. Sensitivity to High Inflation Observations ............................................ 13

C. Sensitivity to the Location of the Threshold ............................................ $\frac{13}{14}$

D. Sensitivity to Data Frequency ........................................................... 14

E. Sensitivity to Additional Explanatory Variables .................................... $\underline{15}$

VI. Conclusions..................................................................................................... 16

Tables

1. Test Results of Threshold Effects (5-Year Average) …........................................... $\underline{8}$

2. GLS With Fixed Effects (5-Year Average) ................................................... 18

3. Numerical Illustration of the Effects of Inflation on Growth .............................. 19

4. 2SLS With Fixed Effects (5-Year Average) ................................................. 20

5. GLS Without Fixed Effects (5-Year Average) ................................................. 21

6. GLS With Fixed Effects (5-Year Average): Excluding Observations

With Inflation Greater Than 40 Percent.......................................................... 22

7. GLS With Fixed Effects (Yearly Data) ...................................................... 23

Figures

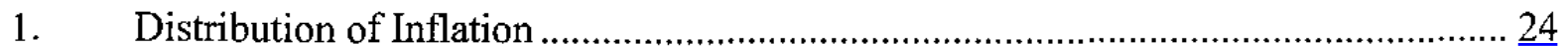

2. Relationship Between Real GDP Growth and Inflation ................................. 25

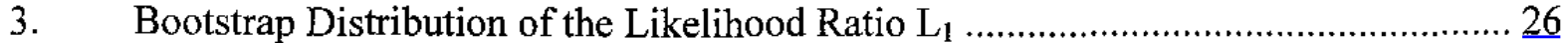

4. Confidence Interval for Threshold Estimate (5-Year Average) ............................ 27

5. Sensitivity of the Effect of Inflation on Growth to the Threshold Level

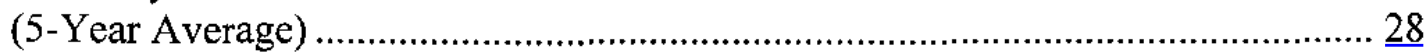

6. Confidence Interval for Threshold Estimate (Yearly Data) ................................. 29

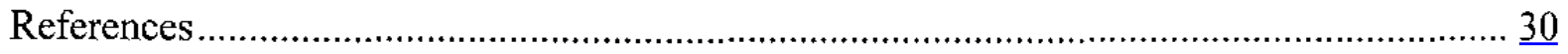




\section{INTRODUCTION}

A high and sustained growth of ouput in conjunction with low inflation is the central objective of macroeconomic policy. Not surprisingly, the question of the existence and nature of the link between inflation and growth has been the subject of considerable interest and debate. Although the debate about the precise relationship between these two variables is still open, the intensive research on this issue has uncovered some important results and a relatively wide consensus about some aspects of this relationship has been reached. It is generally accepted now that inflation has a negative effect on medium and long-term growth. ${ }^{2}$ Inflation impedes efficient resource allocation by obscuring the signalling role of relative price changes, the most important guide to efficient economic decisionmaking Fischer (1993). ${ }^{3}$

If inflation is inimical to growth, it readily follows that policymakers should aim at a low rate of inflation. But how low should inflation be? Should the target inflation be 10 percent, 5 percent, or for that matter, zero percent? More generally, at what level of inflation does the relationship between inflation and growth become negative?

These are the questions that several recent empirical studies have examined, focusing specifically on whether the relationship between inflation and long-run growth is a nonlinear one. ${ }^{4}$ In other words, at some (low) rate of inflation, the relationship could be positive or nonexistent, but at higher rates it becomes negative. If such a nonlinear relationship exists then it should be possible in principle to estimate the inflexion point, or threshold, at which the sign of the relationship between the two variables would switch. The possibility of such a nonlinear relationship was first identified by Fischer (1993), who noted the existence of a positive relationship at low rates of inflation and a negative one as inflation rose (which weakened as inflation increased). Sarel (1996) specifically tested for the existence of a structural break in the relationshionship between inflation and growth and found evidence of

${ }^{2}$ See Barro (1991), Fischer (1983,1993), Bruno and Easterly (1998), and Sbordone and Kuttner (1994). This link between low inflation and high growth has also been found by various regional studies, for example, by De Gregorio (1992) for Latin America, Hadjimichael, Ghura, and others (1995) for Sub-Saharan Africa, and Fischer, Sahay, and Vegh (1996) for transition economies.

${ }^{3}$ It has been argued that what matters for efficient resource allocation is not so much the level of inflation but its variance. However, to the extent that the variance of inflation is positively related to its level-see Bulkley (1984), Ball (1992), Grier and Perry (1996), and $\mathrm{Ma}(1998)$ - the latter does affect resource allocation. While theory seems to suggest that the variability of inflation should affect growth more than its level, empirical studies show the opposite result (see Fischer 1993).

${ }^{4}$ See, for example, Fischer (1993), Sarel (1996), Ghosh and Phillips (1998), Christoffersen and Doyle (1998), and Bruno and Easterly (1998). 
a significant structural break at an annual inflation rate of 8 percent. Below that rate, inflation does not have a significant effect on growth, or it may even exhibit a slightly positive effect. For inflation rates greater than 8 percent, the effect is negative, statistically significant, and strong. Ignoring the existence of this threshold substantially biases the effect of inflation on growth. Ghosh and Phillips (1998), using a larger sample than Sarel's, find a substantially lower threshold effect at 2.5 percent annual inflation rate. They also find that inflation is one of the most important statistical determinants of growth. Christoffersen and Doyle (1998) estimate the threshold level at 13 percent for transition economies. Bruno and Easterly (1998) argue that the negative relationship between inflation and growth, typically found in crosscountry regressions, exists only in high-frequency data and with extreme inflation observations. They find no cross-sectional correlation between long-run averages of growth and inflation in the full sample, but detect a negative effect of inflation and growth for inflation rates higher than 40 percent. $^{5}$

This paper reexamines the nature of the relationship between inflation and growth. Specifically, it focuses on the following questions:

- Is there a statistically significant threshold level of inflation above which inflation affects growth differently than at lower inflation rates?

- Is the threshold effect similar across developing and industrial countries?

- Considering that the studies discussed above arrive at different threshold estimates, are these threshold values statistically different?

- How robust is the Bruno-Easterly finding that the negative relationship between inflation and growth exists only for high-inflation observations and for high-frequency data?

These questions are examined using new econometric methods for threshold estimation and inference. ${ }^{6}$ There are two particular econometric issues related to the estimation and inference in models with threshold effects. First, the asymptotic distribution of the $t$-statistic on the threshold variable is nonstandard and requires bootstrap methods to compute its significance level. Second, methods need to be developed to conduct inference in the context of panel models with threshold effects.

Section II discusses data issues, Section III describes the estimation method, Section IV presents the results, Section V checks the robustness of the results, and Section VI provides some concluding remarks.

${ }^{5}$ This finding has been confirmed in a separate study by Easterly (1996).

${ }^{6}$ These techniques have been developed by Bruce Hansen. See Hansen (1999, 2000). 


\section{Data Issues}

The dataset includes 140 countries (comprising both industrial and developing countries) and generally covers the period 1960-98. Data for a number of developing countries, however, have a shorter span. Because of the uneven coverage, the analysis is conducted using unbalanced panels. The data come primarily from the World Economic Outlook (WEO) database and includes the following variables: the growth rate of GDP in local currency in constant 1987 prices, inflation computed as the growth rate of the CPI index, the initial income level measured as the five-year average of GDP per capita in 1987 PPP prices, gross domestic investment as a share of GDP, population growth, the growth rate of terms of trade, and the five-year standard deviation of terms of trade.

The first panel in Figure 1 shows the distribution of inflation across the full sample of countries and time periods. It is clear that the distribution is highly skewed. A regression of real GDP growth on the level of inflation would give much weight to the extreme inflation observations, even though the bulk of the observations correspond to low and medium inflation rates. As suggested by Sarel (1996), the log transformation eliminates, at least partially, the strong asymmetry in the inflation distribution (see second panel in Figure 1). In the class of nonlinear models, Ghosh and Phillips (1998) show that the log transformation provides the best fit. Finally, the log transformation can be justified by the fact that its implications are more plausible than that of a linear model. In particular, the linear model implies that additive inflation shocks will have identical effects on growth in low- and highinflation economies, while the log model implies that multiplicative inflation shocks will have identical effects on low- and high-inflation economies. For example, in the linear model, an increase in inflation by 10 percentage points will have the same effect on growth in an economy with an initial inflation rate of 10 percent as in an economy with an initial inflation rate of 100 percent. In the $\log$ model, a doubling of the inflation in those two economies will have the same effect on growth.

Figure 2 shows the relationship between real GDP growth and the logarithm of inflation $(\pi){ }^{7}$ The data have been smoothed out by reducing the full sample to five observations. The latter are the arithmitic means of five equal subsamples corresponding to increasing levels of inflation.

We can see from Figure 2 that the relationship between real GDP growth and the log of inflation is slightly positive for low levels of inflations and becomes negative for higher inflation levels, corroborating the findings of Ghosh and Phillips (1998). Note also that the negative effect of inflation on growth weakens somewhat at higher inflation rates, supporting Fischer's (1993) findings.

\footnotetext{
${ }^{7}$ The use of the $\log$ transformation obviously requires dropping the negative inflation observations (of which there were only few since five-year averaged data are used in this study).
} 


\section{Model Specification and Estrimation}

To test for the existence of a threshold effect, the following model was estimated:

$$
\begin{aligned}
& d \log \left(y_{i t}\right)=\mu_{i}+\mu_{i}+\gamma_{1} \log \left(\pi_{i t}\right)+\gamma_{2} d_{i t}{ }^{*}\left[\log \left(\pi_{i t}\right)-\log \left(\pi^{*}\right)\right]+\theta^{t} X_{i t}+e_{i t} \\
& d_{i t}{ }^{*}=\left\{\begin{array}{l}
1 \text { if } \pi_{i t}>\pi^{*} \\
0 \text { if } \pi_{i t} \leq \pi^{*}
\end{array} \quad i=1, \ldots, N ; \quad t=1, \ldots, T\right.
\end{aligned}
$$

where $d \log \left(y_{i t}\right)$ is the growth rate of real GDP, $\mu_{i}$ is a fixed effect, $\mu_{t}$ is a time effect, $\pi_{i t} i s$ inflation based on the CPI index, $\pi^{*}$ is the threshold level of inflation, $d_{i t}{ }^{{ }^{*}}$ is a dummy variable that takes a value of one for inflation levels greater than $\pi^{*}$ percent and zero otherwise, $X_{i t}$ is a vector of control variables which includes investment as a share of GDP (igdp), population growth $(d \log (p o p))$, the log of initial income per capita $\left(\log \left(y_{i 0}\right)\right)$, the growth rate of terms of trade $(d \log (t o t))$, and the five-year standard deviation of terms of trade $\left(\sigma_{t o t}\right)^{8}$. The index " $i$ " is the cross-sectional index while " $t$ " is the time-series index. For reasons discussed above, inflation appears in logs in equation (1). The subtraction of $\log \left(\pi^{*}\right)$ from $\log \left(\pi_{i}\right)$ makes the relationship between growth and inflation, described by equation (1), continuous at the threshold level $\pi^{* 9}$.

Note that $X_{i t}$ contains only the most important variables among the large set found in the empirical growth literature because very few of these variables pass the robustness tests in Levine and Renelt (1992) and Sala-i-Martin (1997). Furthermore, the model explicitly takes into account the individual country effects through $\mu_{\mathrm{i}}$ and the time effect through $\mu_{\mathrm{t}}$. The effect of inflation on GDP growth is given by $\gamma_{1}$ for countries in which inflation is less or equal to $\pi^{*}$ percent, and $\gamma_{1}+\gamma_{2}$ for countries with inflation rates higher than $\pi^{*}$ percent.

In order to smooth out business cycle fluctuations and focus on medium- and long-term relationship between inflation and growth, equation (1) has been estimated on the five-year average of the panel of 140 countries and 39 annual observations each. Therefore, the time dimension reduces to eight observations: $1960-64,1965-69,1970-74,1975-79,1980-84$, 1985-89, 1990-94, and 1995-98 (the last observation is an average over four observations

\footnotetext{
${ }^{8}$ The growth rate of a variable $x$ is computed as the first difference of $\log (x)$.

${ }^{9}$ Continuity of the relationship given by equation (1) is desirable, otherwise small changes in the inflation rate around the threshold level will yield different impacts on growth depending on whether inflation is increasing or decreasing.
} 
only).$^{10}$ Potentially the dimension of the panel would be $140 \times 8=1120$ observations.

However, because of missing observations, the dimension of the unbalanced panel is smaller. Stacking the observation in vectors yields the following compact notation for equation (1):

$$
d \log (Y)=X \beta_{\pi}+e \quad . \pi=\underline{\pi}, \ldots, \bar{\pi}
$$

where $\beta_{\pi}=\left(\mu_{i} \mu_{t} \gamma_{1} \gamma_{2} \theta^{\prime}\right)^{\prime}$ is the vector of parameters and $X$ is the corresponding matrix of observations on the explanatory variables. Note that the coefficient vector $\beta$ is indexed by $\pi$ to show its dependence on the threshold level of inflation, the range of which is given by $\underline{\pi}$ and $\bar{\pi}$. Define $S_{1}(\pi)$ as the residual sum of squares with the threshold level of inflation fixed at $\pi$. The optimal threshold level $\pi^{*}$ is chosen so as to minimize $S_{l}(\pi)$, that is:

$$
\pi^{*}=\underset{\pi}{\operatorname{argmin}}\left\{S_{1}(\pi), \pi=\underline{\pi}, \ldots, \bar{\pi}\right\}
$$

It is important to determine whether the threshold effect is statistically significant. In equation (1), to test for no threshold effects amounts simply to testing the null hypothesis $\mathrm{H}_{0}: \gamma_{2}=0$. Under the null hypothesis, the threshold $\pi^{*}$ is not identified, so classical tests, such as the $t$-test, have nonstandard distributions. Hansen $(1996,1999)$ suggests a bootstrap method to simulate the asymptotic distribution of the following likelihood ratio test of $\mathrm{H}_{0}$ :

$$
L R_{0}=\left(S_{0}-S_{1}\right) / \hat{\sigma}^{2}
$$

where $S_{0}$, and $S_{1}$ are the residual sum of squares under $\mathrm{H}_{0}: \gamma_{2}=0$, and $\mathrm{H}_{1}: \gamma_{2} \neq 0$, respectively; and $\hat{\sigma}^{2}$ is the residual variance under $\mathrm{H}_{1}$. In other words, $S_{0}$ and $S_{l}$ are the residual sum of squares for equation (1) without and with threshold effects, respectively. The asymptotic distribution of $L R_{0}$ is nonstandard and strictly dominates the $\chi^{2}$ distribution. The distribution of $L R_{0}$ depends in general on the moments of the sample; thus critical values cannot be tabulated. Hansen (1999) shows how to bootstrap the distribution of $L R_{0}$ in the context of a panel.

An interesting question is whether an inflation threshold, for example, of 10 percent is significantly different from a threshold of 8 percent or 15 percent. In other words, can the concept of confidence intervals be generalized to threshold estimates? Hansen (2000) shows that the best way to form a confidence region for $\pi^{*}$ is to form the "no-rejection region" using the likelihood ratio statistic for tests on $\pi$. To test the hypothesis $\mathrm{H}_{0}: \pi^{*}=\pi_{1}$, we compute the following likelihood ratio test:

${ }^{10}$ The initial income variable $l y_{0}$ is computed as the five-year average of real income per capita in PPP terms for the previous five-year period, allowing the identification of $l y_{0}$ under fixed effects. 
$L R_{1}\left(\pi_{1}\right)=\left(S_{1}\left(\pi^{*}\right)-S_{1}\left(\pi_{1}\right)\right) / \hat{\sigma}^{2}$

where $S_{I}\left(\pi^{*}\right)$ and $S_{1}\left(\pi_{I}\right)$ are the residual sum of squares from equation (1) with threshold $\pi^{*}$ and $\pi_{l}$, respectively; and $\hat{\sigma}^{2}$ is the residual variance from equation (1) with threshold $\pi_{l}$. Note that $\mathrm{LR}_{0}$ tests the existence of a threshold effect while $L R_{I}$ tests the equality of two potential thresholds. Hansen (2000) shows that $L R_{l}\left(\pi_{l}\right)$ converges in distribution to $\xi$ as $N \rightarrow \infty$, where $\xi$ is a random variable with the following simple distribution function $P(\xi \leq x)=(1-\exp (-x / 2))^{2}$ which can be inverted to yield $c(\alpha)=-2 \log (1-\sqrt{1-\alpha})$, where $c(\alpha)$ is the $\alpha$ percent critical value. A test $\mathrm{H}_{0}: \pi^{*}=\pi_{1}$ rejects at the asymptotic level $\alpha$ if $L R_{I}\left(\pi_{l}\right)$ exceeds $c(\alpha)$.

Under $\mathrm{H}_{1}$, the standard hypothesis tests on all parameters other than the threshold inflation parameter can be carried out as usual.

\section{ESTIMATION AND INFERENCE RESULTS}

\section{A. Test for Existence of Threshold Effects}

The first step is to test for the existence of a threshold effect in the relationship between real GDP growth and inflation using the likelihood ratio, $L R_{0}$, discussed above. This implies estimating equation (1) and computing the residual sum of squares (RSS) for threshold levels of inflation ranging from $\underline{\pi}$ to $\bar{\pi}$. The optimal threshold level is the one that minimizes the sequence of RSSs. The test for the existence of threshold effects has been conducted using the full sample and two subsamples (industrial and developing countries). The tests results are summarized in Table 1:

Table 1. Test Results of Threshold Effects

\begin{tabular}{lccccc}
\hline \multicolumn{1}{c}{ Sample } & $\begin{array}{c}\text { Search Range } \\
\text { for Thresholds }\end{array}$ & $\begin{array}{c}\text { Optimal } \\
\text { Threshold (\%) }\end{array}$ & LR $_{0}$ & $\begin{array}{c}\text { Critical } \\
\text { Value (1\%) }\end{array}$ & $\begin{array}{c}\text { Significance } \\
\text { Level }\end{array}$ \\
\hline All Countries & $\{1,2,3, \ldots, 100\}$ & 11 & 10.59 & 7.47 & 0.001 \\
Industrial Countries & $\{1,2,3, \ldots, 30\}$ & 1 & 8.80 & 6.63 & 0.005 \\
Developing Countries & $\{1,2,3, \ldots, 100\}$ & 11 & 10.89 & 6.21 & 0.000 \\
\hline
\end{tabular}

The first column gives the range over which the search for the optimal threshold effect is conducted. For the full sample, $\underline{\pi}=1$ percent, $\bar{\pi}=100$ percent, and the increment is 
1 percent, which yields 100 panel regressions of equation (1). ${ }^{11}$ The minimization of the vector of 100 RSSs occurs at the inflation level of 11 percent. Repeating the same procedure for the subsamples yields a threshold estimate of 11 percent for developing countries and 1 percent for industrial countries. Note that the threshold level for industrial countries is much lower. ${ }^{12}$ The column $L R_{0}$ in Table 1 gives the observed value of the likelihood ratio. The significance levels have been computed using the bootstrap distributions (corresponding to the three samples) of $L R_{0 .}{ }^{13}$ Figure 3 shows the graph and provides the main statistics of the bootstrap distributions. The null hypothesis of no threshold effects can be rejected at least at the 1 percent significance level for all three samples. Thus the data strongly support the existence of threshold effects.

Having established the existence of a threshold for all three samples, the next important question is how precise are these estimates? This requires the computation of the confidence region around the threshold estimate. While the existence of threshold effects in the relationship between inflation and growth is well accepted, the precise level of the inflation threshold is still subject to debate. Indeed, as discussed earlier, based on existing studies, the range could be between 2.5 percent and 40 percent. If the confidence region shows that the threshold estimate is not significantly different from a large number of other potential threshold levels, that would imply that there is substantial uncertainty about the threshold level. Figure 4 gives the confidence region for the threshold estimate. The three panels correspond to the three samples. The confidence region is constructed using the likelihood ratio $L R_{l}$ defined by equation (5). More specifically, the curve depicts $L R_{l}(\pi)$ for $\pi=\{1,2, \ldots, 100\}$, except for industrial countries in which the range is $\pi=\{1,2, \ldots, 30\}$. By construction, $L R_{l}$ reaches zero (the minimum) when $\pi$ is equal to the threshold estimate. The horizontal line shows the 10 percent asymptotic critical value for $L R_{l}$, computed using the formula for $c(\alpha)$ given above. The no-rejection region of confidence $1-\alpha$ is the set of values of $\pi$ such that $L R_{l}(\pi) \leq c(\alpha)$. Consequently, the confidence region is simply the set of values of $\pi$ for which $L R_{l}(\pi)$ lies below the horizontal line.

\footnotetext{
${ }^{11}$ For industrial countries the upper bound has been set to 30 percent as almost all observations for these countries lie below that inflation level.
}

${ }^{12}$ Since $L R_{l}(\pi)$ reaches its minimum at 1 percent (the lowest value in the range) for developed countries, the question is whether the minimum is an interior or a corner solution. In other words, is the minimum at 1 percent or less than 1 percent? This question cannot be answered with five-year-averaged observations as only eight observations have an inflation rate below 1 percent for industrial countries. However, this question will be reexamined in the next section with yearly data that provide more observations with low inflation.

${ }^{13}$ For a more detailed discussion on the computation of the bootstrap distribution of $L R_{0}$, see Hansen (1999). 
Contrary to the usual confidence intervals, confidence regions for thresholds may not be compact. For example, the $L R_{I}$ curve could cross the horizontal line many times, outlining several subsets of potential thresholds. The values of $\pi$ for which $\mathrm{LR}_{1}$ is above the horizontal line are significantly different from the threshold estimate. Interestingly, the confidence region is relatively wide for developing countries, which implies that the threshold estimate for developing countries is imprecise and may explain why different studies obtained different estimates. The 90 percent confidence region includes inflation rates in the $[1,19]$ interval for developing countries and the full sample, and in the $[1,4]$ interval for industrial countries. It is clear from these results that the threshold estimate for industrial countries occurs at a lower inflation rate than for developing countries, and that the confidence region for the former is tighter than for the latter.

Two basic conclusions can be drawn from this set of statistical tests. First, the threshold is around an inflation rate of 1 percent for industrial economies and 11 percent for developing countries. Second, the confidence region is relatively wide for developing countries pointing to the uncertainty about the exact location of the threshold for these countries. In contrast, the confidence region for industrial countries is much tighter, and thus the threshold estimate is much more precise than for developing countries. One needs to ask why the threshold level for developing countries is higher than the threshold level for industrial countries. There are at least two possible conjectures that we can make. First, the long history of inflation in many developing countries led them to adopt widespread indexation systems to negate, at least partially, the adverse effects of inflation. Once in place, these indexation mechanisms make it possible for governments in these countries to run higher rates of inflation without experiencing adverse growth effects (because relative prices do not change that much). Second, to the extent that inflation is viewed as a tax on financial intermediation, governments, faced with a target level of expenditure will, in the absence of conventional taxes, levy the inflation tax. Accordingly, the differential threshold levels for the effects of inflation on growth for industrial and developing countries could reflect the higher level of conventional taxation in the former than in the latter. Thus, while relatively small increases in inflation in industrial countries adversely affect investment (by raising the effective cost of capital goods), productivity, and growth, in developing countries, with relatively low levels of conventional taxes, a larger inflation tax is required to have the same growth-inhibiting effects. $^{14}$

\section{B. Estimation Results}

Table 2 provides the estimation results of equation (1), conditional on the threshold estimates of the previous section, for the three samples. To take the significant heteroskedasticity in the panel into account, equation (1) has been estimated using Generalized Least Squares (GLS).

\footnotetext{
${ }^{14}$ Roubini and Sala-i-Martin (1995) and Cukierman, Edwards, and Tabellini (1992) have developed models that yield results along these lines. We are grateful to Paul Cashin and John McDermott for bringing this possible explanation to our attention.
} 
Fixed effects and time dummies have been included (but not reported) to control for crosscountry heterogeneity and time effects. For the full sample, for which the threshold estimate is 11 percent, all coefficients have the right sign and are statistically significant at the 1 percent level. Recall that the existence of a threshold effect cannot be inferred simply from the significance level of the coefficient on the interactive term $d^{\pi^{*}}\left[\log (\pi)-\log \left(\pi^{*}\right)\right]$ as the distribution of the $t$-statistic for this variable is highly nonstandard under the null hypothesis of no threshold effect. This is why the null hypothesis has been tested using the bootstrap distribution of the likelihood ratio $L R_{l}(\pi)$. However, the distribution of the $t$-values of all explanatory variables retain their usual distribution under the alternative hypothesis of a threshold effect. While inflation below its threshold level has a small positive effect on growth, inflation rates above the threshold level have a significant negative effect on growth.

Dividing the sample into industrial and developing countries highlights some interesting insights. First, both groups show a positive and statistically significant relationship between growth and inflation below the threshold level and a significant and a more powerful negative relationship for inflation rates above the threshold. As expected, investment as a share of GDP and population growth have a positive and significant effect on growth. On average, an increase in the investment-GDP ratio of 5 percentage points will boost real GDP growth by 0.74 percentage points for developing countries and by 0.69 percentage points for industrial countries. In the empirical growth literature, the log of the initial GDP per capita $\left(y_{0}\right)$ has been generally included in growth regressions to test conditional convergence. Conditional convergence holds if the coefficient on $l y_{0}$ is negative. ${ }^{15}$ Thus, convergence occurs for both the full sample and for industrial countries. The rate of convergence among industrial countries is faster than for the full sample of countries, corroborating the results of previous studies, which find that conditional convergence is much stronger among industrial countries. ${ }^{16}$

The first three panels of Table 3 illustrate the regression results in Table 2 for the full sample, for industrial countries, and for developing countries, respectively. The three panels show the effect on growth of gradually increasing inflation for a hypothetical economy with initial inflation rate of 3 percent. ${ }^{17}$ The maximum growth that a developing country, with an initial inflation rate of 3 percent, can gain through further inflation is 0.16 percentage points (by moving from an annual inflation rate of 3 percent to 11 percent). This magnitude very likely overestimates the positive effect of inflation as investment over GDP (igdp) was held constant while moving inflation from 3 to 11 percent. However, Fischer (1993) has shown

${ }^{15}$ A negative coefficient on $l y_{0}$ implies that countries with initially low income per capita tend to grow faster than countries with higher income per capita.

${ }^{16}$ See, for example, Mankiw, Romer, and Weil (1992).

${ }^{17}$ The shaded areas in Table 3 indicate inflation rates that are above the threshold level of inflation. 
that inflation also has a negative and significant indirect effect on growth through its effect on investment. This indirect effect is not taken into account here. From our results, the positive effect rapidly changes into a negative one as inflation increases above the threshold. For example, an increase in inflation from 3 to 30 percent will reduce growth by 0.67 percentage points in developing countries and by 0.95 percentage points in industrial countries. The effect of inflation on growth for any pair of inflation rates in the first column is simply equal to the difference between their growth effects. For example, reducing a developing country's annual inflation rate from 60 percent to 15 percent will increase its GDP growth by 1.15 percentage points. The log transformation implies that the effect on growth will be identical for an economy that moves from a 3 percent inflation rate to 6 percent and an economy that increases its inflation rate from 4 percent to 8 percent. This is because, in both cases, the inflation rate is doubled. Of course, this property holds only for inflation changes that do not induce a crossing of the threshold.

\section{RobUSTNESS}

\section{A. Sensitivity to the Estimation Method}

\section{Potential endogeneity of inflation and investment}

Inflation may not be an exogenous variable in the growth-inflation regression, and the coefficient estimates may thus be biased. The seriousness of this problem will depend, to a large extent, on whether the causality runs mainly from inflation to growth, in which case the endogeneity problem may be benign, or the other way around, in which case the problem may be more severe. As argued by Fischer (1993), the causality is more likely to run predominantly from inflation to growth, in which case the problem of simultaneity bias may not be very important. Similarly, investment (as share of GDP) is also likely to be endogenous to growth. In order to control, at least partially, for this problem the model has also been estimated using Two-Stage Least Squares (2SLS), where both inflation and investment are treated as potentially endogenous to growth. The set of instruments for inflation (infl) includes the lag of inflation, the lag of real GDP growth, the lag of the growth rate of $\mathrm{M} 2$, the growth rate of terms of trade, and a time trend. ${ }^{18}$ The same instruments were used for investment as a share of GDP ( $i g d p$ ) except that the lag of inflation is replaced by the lag of igdp. The results are presented in Table 4.

The main insight from the comparison of Table 2 (GLS estimates) and Table 4 (2SLS estimates) is that the difference between the threshold estimates for developing and industrial countries is narrowed but remains significant. These estimates are 2 percent (versus 1

\footnotetext{
${ }^{18}$ The lag of inflation, growth, and investment as share of GDP are valid instruments only if the error term in equation (1) is not autocorrelated. A formal test rejects autocorrelation at 10 percent or less for all samples.
} 
percent) for industrial countries and 7 percent (versus 11 percent) for developing countries. The negative effect of inflation strengthens for industrial countries above the threshold level of inflation. The positive but statistically insignificant effect of inflation on growth for developing countries below the threshold level of 11 percent turns into an insignificant negative effect when instruments are used for infl and igdp.

\section{Sensitivity to fixed effects}

Since panel estimation can be quite sensitive to the use of fixed effects, equation (1) has also been estimated without fixed effects. Tables 2 and 5 show similar results. In particular, the estimates of threshold levels are identical. However, omitting fixed effects significantly weakens the negative effect of inflation on growth for developing countries above the threshold level of inflation, and underestimates the rate of convergence among countries.

\section{B. Sensitivity to High-Inflation Observations}

Bruno and Easterly (1998) and Easterly (1996) have argued that the negative relationship between inflation and growth holds only for high-inflationary economies. They show that excluding observations with annual inflation rates of 40 percent or more weakens the negative relationship between inflation and growth. Their methodology differs from ours in that theirs is not based on regression analysis but on mean comparison before, during, and after inflation crises (defined as inflation episodes above 40 percent). To test their hypothesis within our framework, equation (1) was reestimated with five-year-averaged data excluding observations with inflation rates higher than 40 percent. The results are presented in Table 6 .

The results turn out to be very close to the estimates with the full sample (given in Table 2). The threshold estimates are almost identical and the threshold effects are even more significant without high inflation observations for developing countries. ${ }^{19}$

\section{Sensitivity to the Location of the Threshold}

Figure 5 shows the sensitivity of the effect of inflation on growth when the threshold level varies from 1 percent to 100 percent. The three panels (corresponding to the three samples) depict the effect of inflation on growth for economies with an inflation rate below the threshold level (solid line) and for economies with inflation rates above the threshold level (dotted line). These effects are given by the coefficients $\gamma_{1}$ and $\gamma_{1}+\gamma_{2}$ in equation (1). The vertical line indicates the threshold estimate. The following points emerge from Figure 5: (i) the high- and low-inflation effects are most sensitive to the location of the threshold over the

${ }^{19}$ In Table 6 , the elimination of observations with inflation rates above 40 percent restricts the grid over which the search for threshold effects can be conducted. The grids are 1 to 35 percent inflation rate for the full sample and developing countries, and 1 to 20 percent for industrial countries. 
1 to 20 percent range; (ii) the positive effect of inflation on growth is only present for inflation rates lower than 5 percent for industrial countries and 18 percent for developing countries; (iii) for developing countries, the inflation effect on growth, which is negative over the whole range, strengthens as the threshold increases, which implies a worsening of the negative effect of inflation on growth as inflation increases; and (iv) for industrial countries, the inflation effect, while remaining negative over the entire range, first weakens (in absolute value) as the inflation threshold increases, reaches a minimum around a threshold of 15 percent, and strengthens thereafter.

\section{Sensitivity to Data Frequency}

The estimation and inference in the previous section were based on five-year averages of the data. This procedure has become common practice in empirical growth literature and aims at filtering out business cycle fluctuations and allowing the focus to be on the medium- and long-term trend in the data. Threshold estimation and estimation of equation (1) have also been carried out with annual data in order to examine two issues. First, it is interesting to analyze how data frequency changes the location and the magnitude of the threshold effect and the estimation results of equation (1). Second, while noisier, annual data provide more degrees of freedom, especially at the tails of the distribution for inflation. In particular, the inflation threshold for industrial countries was estimated at 1 percent, which was the lower bound of the grid search for threshold effects. The question raised earlier was whether the threshold was at 1 percent or less than 1 percent. With the five-year averages, there was not enough observations with inflation less than 1 percent, whereas annual data provide enough low inflation observations to answer the question.

Table 7 gives the threshold estimate and estimation results of equation (1). ${ }^{20}$ A comparison of Tables 2 and 7 reveals some interesting facts. First, the threshold estimates are somewhat different but very close. The threshold estimates with yearly data are slightly higher for both industrial and developing countries ( 3 percent versus 1 percent for industrial countries, and 12 percent versus 11 percent for developing countries). Second, the high-inflation effect (that is, $\gamma_{1}+\gamma_{2}$ ) is more powerful for yearly data, especially for industrial countries. This is illustrated in the last three columns of Table 3. Third, the low-inflation effect (coefficient $\gamma_{1}$ in equation 1), which was positive and statistically significant for industrial countries for the five-year-averaged data, becomes negative and statistically insignificant. As expected, the fit is poorer with yearly data.

${ }^{20}$ There is a small difference in the specification of equation (1) reported in Tables 2 and 7. In Table 2, equation (1) has the five-year standard deviation of terms of trade as explanatory variable, whereas in Table 7 , it is replaced by the growth rate of terms of trade since the standard deviation cannot be computed for yearly data. If both variables are included in equation (1), when estimated with five-year-averaged data, both variables become insignificant. 
Figure 6 shows the 90 percent confidence region for the threshold estimates. The confidence regions are wider for yearly data reflecting the noisier nature of high-frequency data. The confidence intervals are 1 to 12 percent for industrial countries (versus 1 to 4 percent for the five-year-averaged data), 3 to 36 percent for developing countries (versus 1 to 19 percent), and 3 to 30 percent for the full sample (versus 1 to 20 percent).

Interestingly, the threshold estimate for industrial countries is 3 percent (versus 1 percent with smoothed data). Considering the few number of observations with very low inflation rates for the five-year-averaged data, the 3 percent threshold estimate for industrial countries may be more reliable.

\section{E. Sensitivity to Additional Explanatory Variables}

As explained in Section II, only variables that were found to be robust in the empirical growth literature were included in the regression equation linking inflation to growth. The use of fixed effects also helps capture cross-country differences in GDP growth. Since endogenous growth theory has emphasized the role of human capital in the growth process of a country, equation (1) has been augmented by including a proxy for human capital. Following the empirical growth literature, human capital is proxied by enrollment rates in the primary, secondary, and tertiary schools. ${ }^{21}$ All three variables came out statistically insignificant. Furthermore, their inclusion does not significantly change the results. In fact, the threshold values remain the same. The reason may be that the three proxies (primary, secondary, and tertiary enrollment) are highly correlated with the initial income variable $\left(l y_{0}\right)$. A regression of the former on the latter yields an $\mathrm{R}^{2}$ of $0.98,0.92$, and 0.98 , respectively. In other words, the initial income variable appears to be picking up most of the cross-country variation in school enrollment.

Financial development is another important variable that was emphasized by King and Levine (1993). Following the latter, we used three different proxies for financial depth. The first measures the size of the formal financial intermediary sector relative to economic activity (the ratio of liquid liabilities of the financial system, measured by M3 when it is available and M2 otherwise, to GDP); the second measures the proportion of credit allocated to the private sector (the ratio of claims on the nonfinancial private sector to total domestic credit); ${ }^{22}$ and the third is simply the second normalized by GDP instead of total domestic credit. Adding these variables does not change the estimated threshold values at all.

21 The data on enrollment were taken from the World Bank's Global Development Network Growth Database maintained by William Easterly and Hairong Yu.

${ }^{22}$ Data for these variables were taken from the International Financial Statistics (IFS).

Claims on the nonfinancial private sector is IFS line $32 \mathrm{~d}$ and domestic credit is IFS lines $32 \mathrm{a}$ to $32 \mathrm{f}$ excluding $32 \mathrm{e}$. 


\section{Conclusions}

This paper reexamines the issue of the existence of threshold effects in the relationship between inflation and growth using new econometric techniques that provide appropriate procedures for estimation and inference. The data cover 140 developing and industrialized countries for the period $1960-98 .^{23}$ To eliminate short-term fluctuations, the data have been averaged over periods of five years.

The empirical results strongly suggest the existence of a threshold beyond which inflation exerts a negative effect on growth. The threshold is lower for industrial than for developing countries (the estimates are 1-3 percent and 7-11 percent for industrial and developing countries, respectively, depending on the estimation method). The thresholds are statistically significant at 1 percent or less. However, confidence regions are relatively wide for developing countries, leaving some uncertainty about the exact location of the threshold. The 90 percent confidence region includes inflation rates in the 1 to 4 percent interval for industrial countries and 1 to 20 percent interval for developing countries. This may well explain the lack of consensus for the threshold level in previous studies.

The negative and significant relationship between inflation and growth for inflation rates above the threshold level is robust with respect to the estimation method, perturbations in the location of the threshold level, the inclusion or exclusion of high inflation observations, data frequency, and alternative specifications. Interestingly, using yearly data yields threshold levels that are close to the estimates from the five-year-averaged data (12 percent for developing countries and 3 percent for industrial countries) and a much stronger negative relationship between inflation and growth. ${ }^{24}$ Thus, as in Bruno and Easterly (1998), the relationship between inflation and growth is stronger at high frequencies. At the same time, our results suggest a strong and negative effect of inflation on growth even when data have been averaged over five years.

While the results are informative, some caveats are important to bear in mind when interpreting these results. First, the estimated relationship between inflation and growth does not provide the precise channels through which inflation affects growth, beyond the fact that it is primarily through productivity since investment and employment are controlled for. ${ }^{25}$ This also implies that the total negative effect of inflation may be understated. Second, inflation is not an exogenous variable in the growth-inflation regression, and the coefficient

${ }^{23}$ The period is shorter for a large number of developing countries.

${ }^{24}$ The confidence regions for the threshold estimates with yearly data are wider, reflecting the noisier nature of yearly data versus the five-year-averaged data.

${ }^{25}$ Fischer (1993) examines the effects of inflation on investment, employment, and total factor productivity. 
estimates may be biased. The seriousness of this problem will depend, to a large extent, on whether the causality runs mainly from inflation to growth, in which case the endogeneity problem may not be serious, or the other way around, in which case the bias may be strong. As argued by Fischer (1993), the causality is more likely to run predominantly from inflation to growth, in which case the problem of simultaneity bias may not be very important. A comparison of the Generalized Least Squares to the Two-Stage Least Squares estimates, in which both inflation and investment as a ratio of GDP are instrumented for, shows that the simultaneity bias is not serious in our sample. Finally, inflation may have adverse effects on the economy beyond that on growth. These effects have not been considered here and warrant serious study.

In conclusion, policymakers around the world during the last decade or so have recognized that lowering inflation is conducive to improved growth performance. The goal has became one of bringing inflation down to single digits and keeping it there. The results in the paper provide strong empirical confirmation for this view. 
Table 2. GLS With Fixed Effects (5-Year Average)

Dependent Variable: $d \log (g d p)$

\begin{tabular}{|c|c|c|c|}
\hline Independent Variables & All & Industrial & Developing \\
\hline $\log (\pi)$ & $\begin{array}{l}-0.00041 \\
(-0.70)\end{array}$ & $\begin{array}{l}0.03367 \\
(6.63) \mathrm{a}\end{array}$ & $\begin{array}{l}0.00126 \\
(1.54)\end{array}$ \\
\hline$\left.d^{\pi^{*}} * \log (\pi)-\log \left(\pi^{*}\right)\right]$ & $\begin{array}{l}-0.00795 \\
(-6.93) \mathrm{a}\end{array}$ & $\begin{array}{l}-0.03779 \\
(-5.94) a\end{array}$ & $\begin{array}{l}-0.00952 \\
(-6.60) a\end{array}$ \\
\hline$l y_{0}$ & $\begin{array}{l}-0.03093 \\
(-15.39) \mathrm{a}\end{array}$ & $\begin{array}{l}-0.03850 \\
(-6.35) \mathrm{a}\end{array}$ & $\begin{array}{l}-0.02955 \\
(-12.97) \mathrm{a}\end{array}$ \\
\hline$i g d p$ & $\begin{array}{l}0.13870 \\
(14.42) \mathrm{a}\end{array}$ & $\begin{array}{l}0.13750 \\
(5.20) \mathrm{a}\end{array}$ & $\begin{array}{l}0.14750 \\
(12.61) \mathrm{a}\end{array}$ \\
\hline$d \log (p o p)$ & $\begin{array}{l}0.05048 \\
(4.45) \mathrm{a}\end{array}$ & $\begin{array}{l}0.02530 \\
(0.59)\end{array}$ & $\begin{array}{l}0.04972 \\
(4.10) \mathrm{a}\end{array}$ \\
\hline$\sigma_{t o t}$ & $\begin{array}{l}-0.00013 \\
(-4.31) \mathrm{a}\end{array}$ & $\begin{array}{l}-0.00057 \\
(-1.98) b\end{array}$ & $\begin{array}{l}-0.00013 \\
(-3.82) \mathrm{a}\end{array}$ \\
\hline Optimal threshold (\%) & 11 & 1 & 11 \\
\hline $\begin{array}{l}\mathrm{NxT} \\
\mathrm{R}^{2}\end{array}$ & $\begin{array}{l}897 \\
0.43\end{array}$ & $\begin{array}{l}165 \\
0.79\end{array}$ & $\begin{array}{l}732 \\
0.39\end{array}$ \\
\hline
\end{tabular}

Note: The panel has 8 observations $(\mathrm{T})$, that is five-year averages over $1960-98$, for 140 countries $(\mathrm{N})$. The variables are inflation, $\pi$, the log of initial income, $l y_{0}$; gross domestic investment over GDP, igd $p$; the growth rate of population, $d \log ($ pop $)$; and the standard deviation of terms of trade, $\sigma(t o t)$. The dummy variable $d^{\pi^{*}}$ takes one for inflation rates greater than the optimal threshold $\left(\pi^{*}\right)$ and zero otherwise. The $t$-statistics, given between parentheses, are computed from White heteroskedasticity-consistent standard errors. The letters "a", " $\mathrm{b}$ ", "c", indicate statistical significance at 1,5 , and 10 percent, respectively. The growth rate of a variable $x$ is approximated by the first difference of the $\log$ of $x, d \log (x)$. The estimated time dummies and country-specific effects are not reported. 
Table 3. Numerical Illustration of the Effects of Inflation on Growth

(In percent)

$$
\pi_{0}=3 \text { percent }
$$

\begin{tabular}{|c|c|c|c|c|c|c|}
\hline & \multicolumn{3}{|c|}{ 5-Year-Average } & \multicolumn{3}{|c|}{ Yearly Data } \\
\hline & All & Industrial & Developing & All & Industrial & Developing \\
\hline $\begin{array}{r}\text { Threshold } \\
\pi\end{array}$ & $11 \%$ & $1 \%$ & $11 \%$ & $9 \%$ & $3 \%$ & $12 \%$ \\
\hline 4 & -0.01 & 0.12 & 0.04 & -0.02 & 025 & 0.03 \\
\hline 5 & -0.02 & 0.21 & 0.06 & -0.04 & 044 & 0.06 \\
\hline 6 & -0.03 & 0.29 & 0.09 & -0.05 & 060 & 0.08 \\
\hline 9 & -0.05 & 0.45 & 0.14 & -0.08 & 005 & 0.13 \\
\hline 11 & -0.05 & 054 & 0.16 & -0.29 & 41 & 0.15 \\
\hline 15 & 0,0 & 066 & 009 & 0.0 .62 & 49 & 0.14 \\
\hline 20 & 065 & 0.78 & 033 & 0.93 & 164 & 0.52 \\
\hline 25 & 0.74 & 0087 & 0,5 & (1) & 184 & 0.82 \\
\hline 30 & 008 & 005 & 067 & 146 & 109 & 106 \\
\hline 40 & 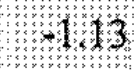 & 107 & 090 & 166 & 2.24 & 1,44 \\
\hline 60 & 4.4 & 4,23 & 424 & 2,10 & 2.59 & 1,98 \\
\hline
\end{tabular}

Note: This Table shows the effect on growth of gradually increasing inflation from an initial inflation rate $\left(\pi_{0}\right)$ of 3 percent to 60 percent, using estimates of the fixed-effects model with yearly and five-year-average data. For example, increasing inflation from 3 percent to 25 percent entails a loss in growth of 1.17 percent using the full sample estimates with yearly data. Shaded areas indicate a crossing of a threshold. 
Table 4. 2SLS With Fixed Effects (5-Year Average)

Dependent Variable: $d \log (g d p)$

\begin{tabular}{|c|c|c|c|}
\hline Independent Variables & All & Industrial & Developing \\
\hline $\log (\pi)$ & $\begin{array}{l}-0.00114 \\
(-2.16) b\end{array}$ & $\begin{array}{l}0.01344 \\
(4.77) \mathrm{a}\end{array}$ & $\begin{array}{l}-0.00014 \\
(-0.21)\end{array}$ \\
\hline$d^{\pi^{*}} *\left[\log (\pi)-\log \left(\pi^{*}\right)\right]$ & $\begin{array}{l}-0.00726 \\
(-7.19) \mathrm{a}\end{array}$ & $\begin{array}{l}-0.02060 \\
(-7.49) \mathrm{a}\end{array}$ & $\begin{array}{l}-0.00888 \\
(-6.43) \mathrm{a}\end{array}$ \\
\hline$y_{0}$ & $\begin{array}{l}-0.03755 \\
(-22.77) \mathrm{a}\end{array}$ & $\begin{array}{l}-0.03154 \\
(-9.04) \mathrm{a}\end{array}$ & $\begin{array}{l}-0.04013 \\
(-20.94) \mathrm{a}\end{array}$ \\
\hline$i g d p$ & $\begin{array}{l}0.14150 \\
(13.16) \mathrm{a}\end{array}$ & $\begin{array}{l}0.14050 \\
(5.71) \mathrm{a}\end{array}$ & $\begin{array}{l}0.13970 \\
(11.34) \mathrm{a}\end{array}$ \\
\hline$d \log (p o p)$ & $\begin{array}{l}0.04383 \\
(4.98) \mathrm{a}\end{array}$ & $\begin{array}{l}-0.03495 \\
(-0.79)\end{array}$ & $\begin{array}{l}0.04989 \\
(5.25) \mathrm{a}\end{array}$ \\
\hline$\sigma_{t o t}$ & $\begin{array}{l}-0.00015 \\
(-5.83) \mathrm{a}\end{array}$ & $\begin{array}{l}-0.00065 \\
(-2.25) b\end{array}$ & $\begin{array}{l}-0.00014 \\
(-4.82) \mathrm{a}\end{array}$ \\
\hline Optimal threshold (\%) & 8 & 2 & 7 \\
\hline $\begin{array}{l}\mathrm{N}_{x} \mathrm{~T} \\
\mathrm{R}^{2}\end{array}$ & $\begin{array}{l}760 \\
0.44\end{array}$ & $\begin{array}{l}127 \\
0.80\end{array}$ & $\begin{array}{l}627 \\
0.42\end{array}$ \\
\hline
\end{tabular}

Note: The panel has 8 observations (T), that is five-year averages over $1960-98$, for 140 countries $(\mathrm{N})$. The variables are inflation, $\pi$, the $\log$ of initial income, $l y_{0}$; gross domestic investment over GDP, igdp; the growth rate of population, $d \log (p o p)$; and the standard deviation of terms of trade, $\sigma(t o t)$. The dummy variable $d^{\pi^{*}}$ takes one for inflation rates greater than the optimal threshold $\left(\pi^{*}\right)$ and zero otherwise. Both infl and igdp have been instrumented for. The list of instruments for infl is a constant, a time trend, the lag of infl, the lag of the growth rate of output, the lag of the growth rate of $M 2$, and the growth rate of terms of trade. The list of instruments for $i g d p$ is the same except that the lag of infl is replaced by the lag of $i g d p$. The $t$-statistics, given between parentheses, are computed from White heteroskedasticity-consistent standard errors. The letters "a", "b", "c", indicate statistical significance at 1,5 , and 10 percent, respectively. The growth rate of a variable $x$ is approximated by the first difference of the $\log$ of $x, d \log (x)$. The estimated time dummies and country-specific effects are not reported. 
Table 5. GLS Without Fixed Effects (5-Year Average)

Dependent Variable: $d \log (g d p)$

\begin{tabular}{|c|c|c|c|}
\hline Independent Variables & All & Industrial & Developing \\
\hline $\log (\pi)$ & $\begin{array}{l}0.00111 \\
(1.82) \mathrm{c}\end{array}$ & $\begin{array}{l}0.02943 \\
(8.58) \mathrm{a}\end{array}$ & $\begin{array}{l}0.00205 \\
(2.53) \mathrm{a}\end{array}$ \\
\hline$d^{\pi^{*}} *\left[\log (\pi)-\log \left(\pi^{*}\right)\right]$ & $\begin{array}{l}-0.00469 \\
(-3.45) \mathrm{a}\end{array}$ & $\begin{array}{l}-0.03412 \\
(-8.17) \mathrm{a}\end{array}$ & $\begin{array}{l}-0.00615 \\
(-3.96) \mathrm{a}\end{array}$ \\
\hline$l y_{0}$ & $\begin{array}{l}-0.00241 \\
(-5.68) \mathrm{a}\end{array}$ & $\begin{array}{l}-0.02553 \\
(-7.38) \mathrm{a}\end{array}$ & $\begin{array}{l}-0.00122 \\
(-1.79) \mathrm{c}\end{array}$ \\
\hline$i g d p$ & $\begin{array}{l}0.11550 \\
(12.93) \mathrm{a}\end{array}$ & $\begin{array}{l}0.09750 \\
(4.67) \mathrm{a}\end{array}$ & $\begin{array}{l}0.10580 \\
(9.56) \mathrm{a}\end{array}$ \\
\hline$d \log (p o p)$ & $\begin{array}{l}0.05894 \\
(7.10) \mathrm{a}\end{array}$ & $\begin{array}{l}0.21917 \\
(11.64) \mathrm{a}\end{array}$ & $\begin{array}{l}0.03717 \\
(3.80) \mathrm{a}\end{array}$ \\
\hline$\sigma_{t o t}$ & $\begin{array}{l}-0.00020 \\
(-3.64) \mathrm{a}\end{array}$ & $\begin{array}{l}-0.00099 \\
(-4.13) \mathrm{a}\end{array}$ & $\begin{array}{l}-0.00019 \\
(-3.55) \mathrm{a}\end{array}$ \\
\hline Optimal threshold (\%) & 11 & 1 & 11 \\
\hline $\begin{array}{l}\mathrm{N}_{x} \mathrm{~T} \\
\mathrm{R}^{2}\end{array}$ & $\begin{array}{l}897 \\
0.20\end{array}$ & $\begin{array}{l}165 \\
0.69\end{array}$ & $\begin{array}{l}732 \\
0.18\end{array}$ \\
\hline
\end{tabular}

Note: The panel has 8 observations (T), that is five-year averages over $1960-98$, for 140 countries $(\mathrm{N})$. The variables are inflation, $\pi$, the log of initial income, $l_{0}$; gross domestic investment over GDP, igdp; the growth rate of population, $d \log (p o p)$; and the standard deviation of terms of trade, $\sigma(t o t)$. The dummy variable $d^{\pi^{*}}$ takes one for inflation rates greater than the optimal threshold $\left(\pi^{*}\right)$ and zero otherwise. The $t$-statistics, given between parentheses, are computed from White heteroskedasticity-consistent standard errors. The letters " $a$ ", "b", " $c$ ", indicate statistical significance at 1,5 , and 10 percent, respectively. The growth rate of a variable $x$ is approximated by the first difference of the $\log$ of $x, d \log (x)$. The estimated time dummies and country-specific effects are not reported. 
Table 6. GLS With Fixed Effects (5-Year Average)

\section{Excluding Observations With Inflation Greater Than 40 Percent}

Dependent Variable: $d \log (g d p)$

\begin{tabular}{|c|c|c|c|}
\hline Independent Variables & All & Industrial & Developing \\
\hline $\log (\pi)$ & $\begin{array}{l}0.00077 \\
(1.41)\end{array}$ & $\begin{array}{l}0.03326 \\
(6.21) \mathrm{a}\end{array}$ & $\begin{array}{l}0.00301 \\
(4.30) \mathrm{a}\end{array}$ \\
\hline$\left.d^{\pi^{*}} * \log (\pi)-\log \left(\pi^{*}\right)\right]$ & $\begin{array}{l}-0.02032 \\
(-16.09) \mathrm{a}\end{array}$ & $\begin{array}{l}-0.03699 \\
(-5.44) \mathrm{a}\end{array}$ & $\begin{array}{l}-0.02453 \\
(-13.94) a\end{array}$ \\
\hline$y_{i}$ & $\begin{array}{l}-0.02741 \\
(-13.50) \mathrm{a}\end{array}$ & $\begin{array}{l}-0.03726 \\
(-6.08) \mathrm{a}\end{array}$ & $\begin{array}{l}-0.02391 \\
(-11.04) \mathrm{a}\end{array}$ \\
\hline$i g d p$ & $\begin{array}{l}0.13500 \\
(14.71) \mathrm{a}\end{array}$ & $\begin{array}{l}0.12460 \\
(4.58) \mathrm{a}\end{array}$ & $\begin{array}{l}0.14260 \\
(12.56) \mathrm{a}\end{array}$ \\
\hline$d \log (p o p)$ & $\begin{array}{l}0.06246 \\
(6.56) \mathrm{a}\end{array}$ & $\begin{array}{l}0.01777 \\
(0.41)\end{array}$ & $\begin{array}{l}0.05972 \\
(6.15) \mathrm{a}\end{array}$ \\
\hline$\sigma_{t o t}$ & $\begin{array}{l}-0.00016 \\
(-3.86) \mathrm{a}\end{array}$ & $\begin{array}{l}-0.00062 \\
(-2.09) \mathrm{b}\end{array}$ & $\begin{array}{l}-0.02391 \\
(-11.04) \mathrm{a}\end{array}$ \\
\hline Optimal threshold (\%) & 12 & 1 & 12 \\
\hline $\begin{array}{l}\mathrm{N}_{x T} \mathrm{~T} \\
\mathrm{R}^{2}\end{array}$ & $\begin{array}{l}831 \\
0.43\end{array}$ & $\begin{array}{l}160 \\
0.80\end{array}$ & $\begin{array}{l}671 \\
0.39\end{array}$ \\
\hline
\end{tabular}

Note: The panel has 8 observations (T), that is five-year averages over 1960-98, for 140 countries $(\mathrm{N})$. The variables are inflation, $\pi$, the log of initial income, $l y_{0}$; gross domestic investment over GDP, igdp; the growth rate of population, $d \log (p o p)$; and the standard deviation of terms of trade, $\sigma(t o t)$. The dummy variable

$d^{\pi^{*}}$ takes one for inflation rates greater than the optimal threshold $\left(\pi^{*}\right)$ and zero otherwise. The $t$-statistics, given between parentheses, are computed from White heteroskedasticity-consistent standard errors. The letters "a", "b", "c", indicate statistical significance at 1, 5 , and 10 percent, respectively. The growth rate of a variable $x$ is approximated by the first difference of the $\log$ of $x, d \log (x)$. The estimated time dummies and country-specific effects are not reported. 
Table 7. GLS With Fixed Effects (Yearly Data)

Dependent Variable: $d \log (g d p)$

\begin{tabular}{|c|c|c|c|}
\hline Independent Variables & All & Industrial & Developing \\
\hline $\log (\pi)$ & $\begin{array}{l}-0.00072 \\
(-1.26)\end{array}$ & $\begin{array}{l}-0.00352 \\
(-0.17)\end{array}$ & $\begin{array}{l}0.00115 \\
(1.49)\end{array}$ \\
\hline$d^{\pi^{*}} *\left[\log (\pi)-\log \left(\pi^{*}\right)\right]$ & $\begin{array}{l}-0.00991 \\
(-9.50) \mathrm{a}\end{array}$ & $\begin{array}{l}-0.00831 \\
(-3.33) \mathrm{a}\end{array}$ & $\begin{array}{l}-0.01446 \\
(-10.47) \mathrm{a}\end{array}$ \\
\hline$i g d p$ & $\begin{array}{l}0.0963 \\
(9.64) \mathrm{a}\end{array}$ & $\begin{array}{l}0.0934 \\
(3.07) \mathrm{a}\end{array}$ & $\begin{array}{l}0.0925 \\
(8.15) \mathrm{a}\end{array}$ \\
\hline$d \log (p o p)$ & $\begin{array}{l}0.05895 \\
(2.51) \mathrm{a}\end{array}$ & $\begin{array}{l}0.00001 \\
(0.00)\end{array}$ & $\begin{array}{l}0.05813 \\
(2.43) \mathrm{a}\end{array}$ \\
\hline $\operatorname{dog}(t o t)$ & $\begin{array}{l}0.00105 \\
(0.27)\end{array}$ & $\begin{array}{l}-0.01602 \\
(-1.47)\end{array}$ & $\begin{array}{l}0.00589 \\
(1.42)\end{array}$ \\
\hline Optimal threshold (\%) & 9 & 3 & 12 \\
\hline $\begin{array}{l}\mathrm{N}_{x \mathrm{~T}} \\
\mathrm{R}^{2}\end{array}$ & $\begin{array}{l}4056 \\
0.15\end{array}$ & $\begin{array}{l}835 \\
0.48\end{array}$ & $\begin{array}{l}3221 \\
0.12\end{array}$ \\
\hline
\end{tabular}

Note: The panel has 8 observations (T), that is five-year averages over $1960-98$, for 140 countries $(\mathrm{N})$. The variables are inflation, $\pi$, gross domestic investment over GDP, igdp; the growth rate of population, $d \log (p o p)$; and the growth rate of terms of trade, $d \log (t o t)$. The dummy variable $d^{\pi^{*}}$ takes one for inflation rates greater than the optimal threshold $\left(\pi^{*}\right)$ and zero otherwise. The t-statistics, given between parentheses, are computed from White heteroskedasticity-consistent standard errors. The letters "a", "b", "c", indicate statistical significance at 1,5 , and 10 percent, respectively. The growth rate of a variable $x$ is approximated by the first difference of the $\log$ of $x, d \log (x)$. The estimated time dummies and country specific effects are not reported. 
Figure 1. Distribution of Inflation

Inflation in Levels

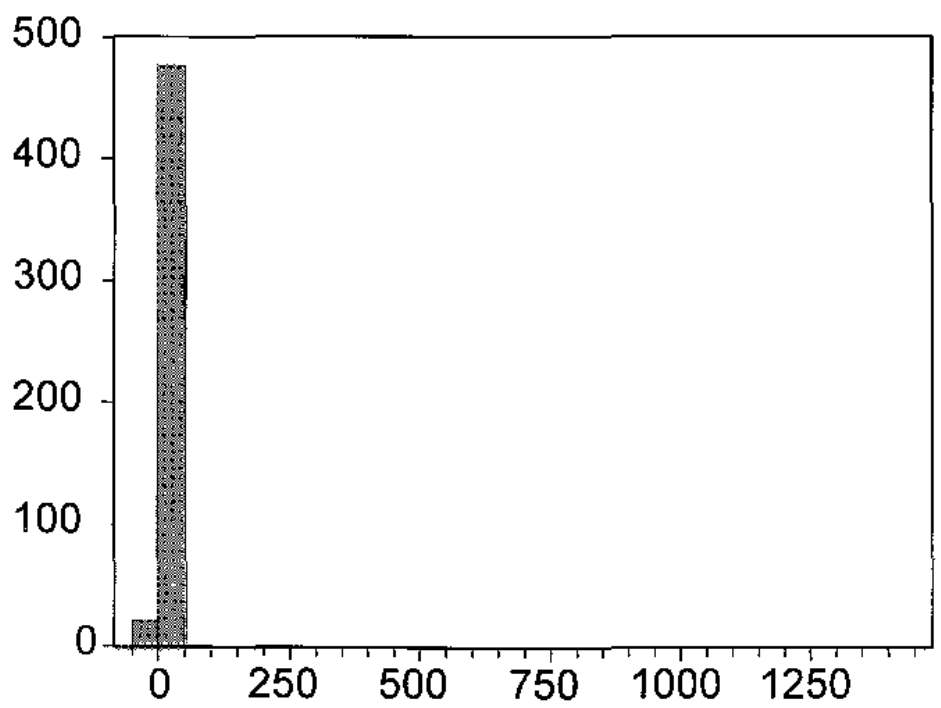

Series: B

Observations 5008

Mean $\quad 28.60558$

Median $\quad 7.480000$

Maximum $\quad 14315.80$

Minimum $\quad-88.58000$

Std. Dev. $\quad 331.7658$

Skewness $\quad 31.23209$

Kurtosis $\quad 1127.011$

The Logarithm of Inflation

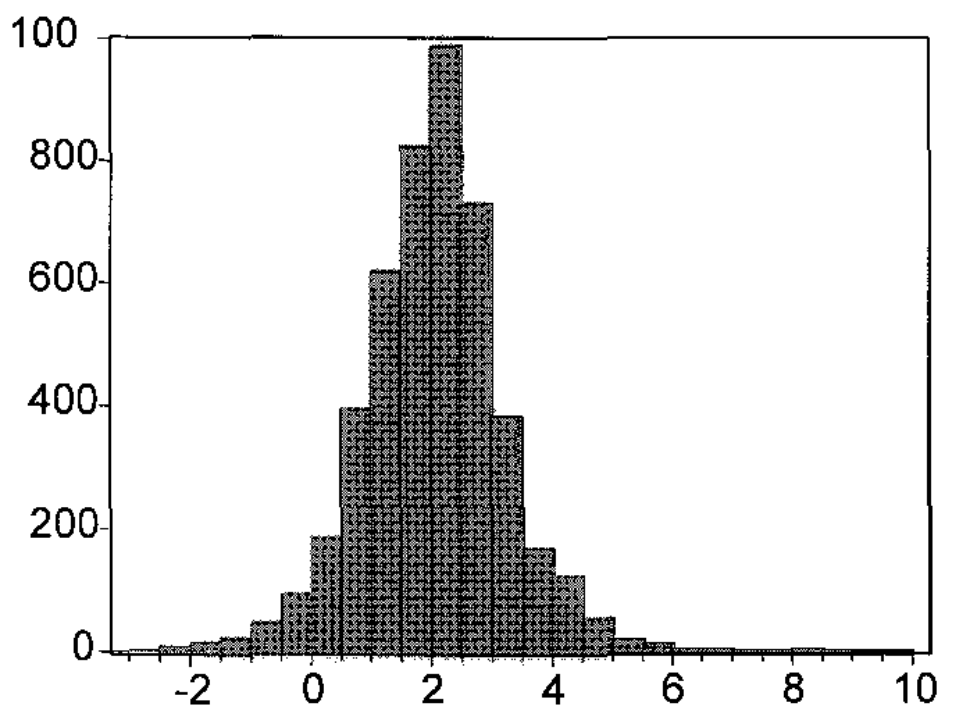

Series: $\log (B)$

Observations 4742

Mean $\quad 2.049372$

Median $\quad 2.073800$

Maximum $\quad 9.569119$

Minimum $\quad-2.995732$

Std. Dev. $\quad 1.203138$

Skewness 0.302993

Kurtosis $\quad 5.866663$ 
Figure 2. Relationship Between Real GDP Growth and Inflation

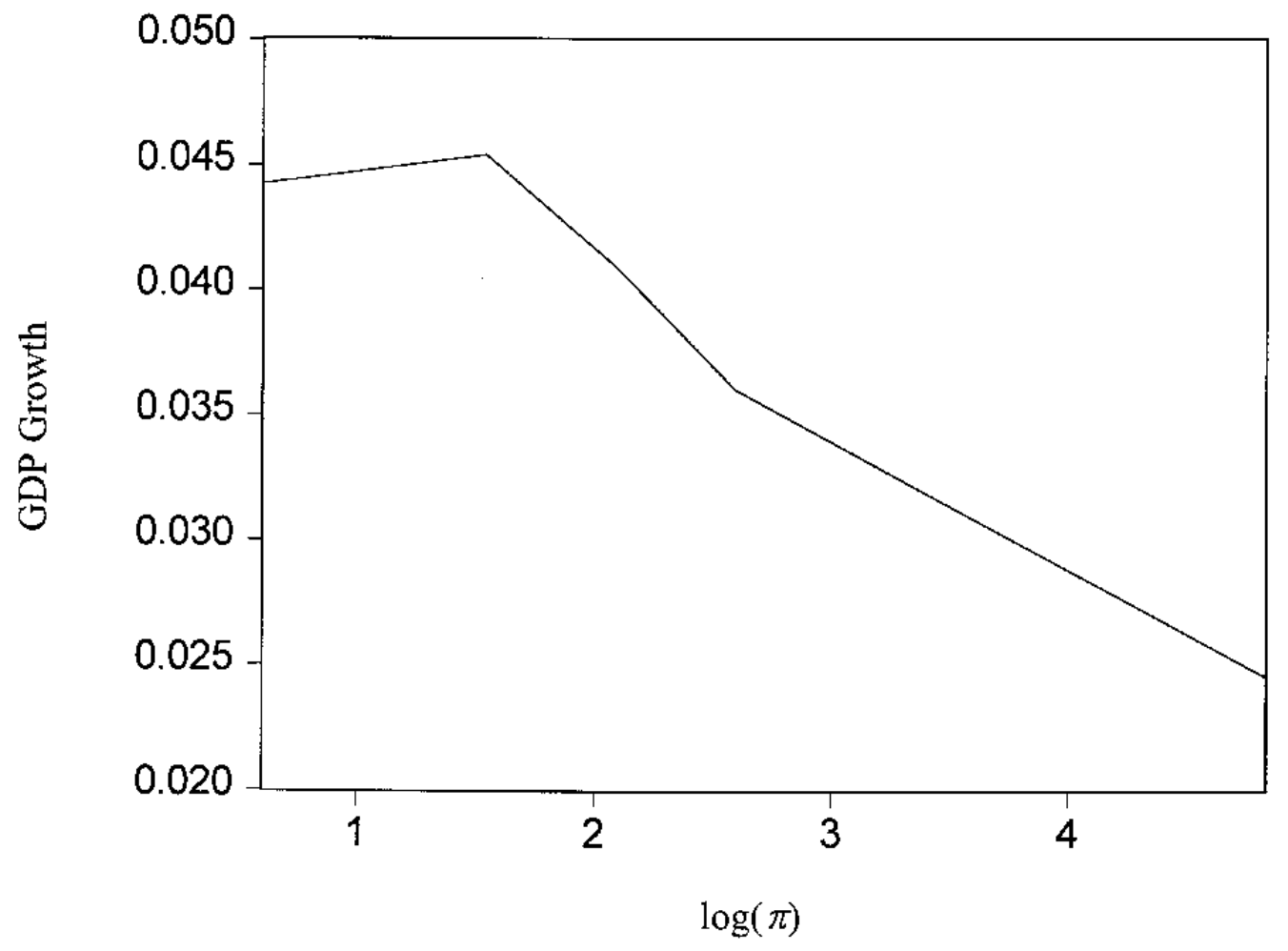


Figure 3. Bootstrap Distribution of the Likelihood Ratio $L_{I}$

Industrial Countries

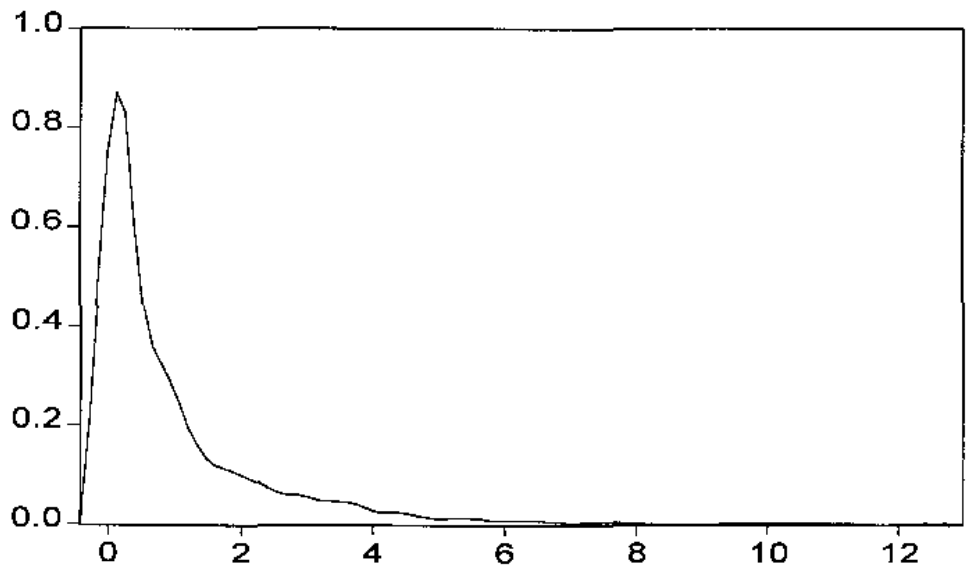

Mean: $\quad 0.976$

Median: $\quad 0.416$

Max.: $\quad 12.546$

Min.: $\quad 2.43 \mathrm{E}-07$

Std.: $\quad 1.438$

Skewness: 3.011

Kurtosis: $\quad 16.160$

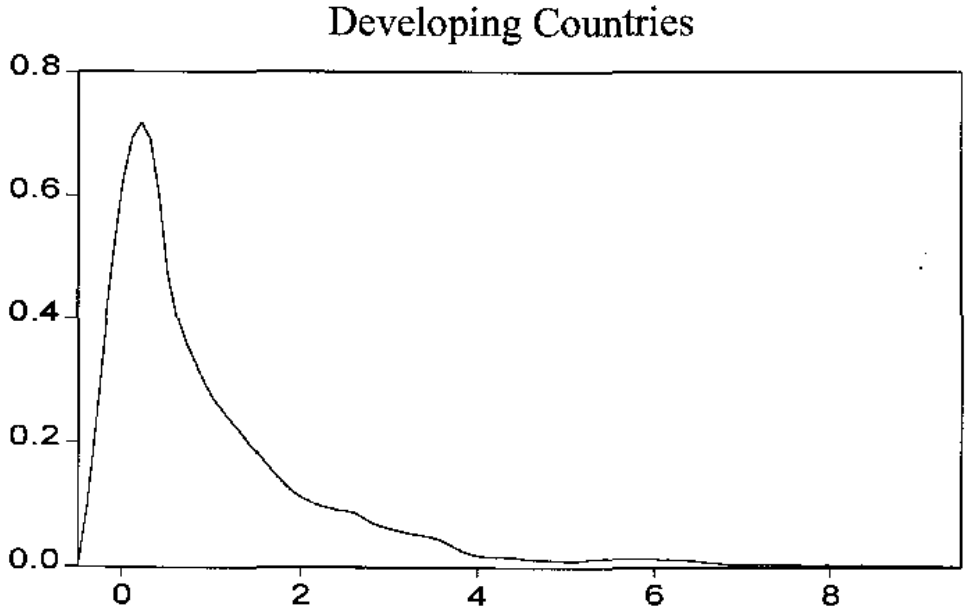

Mean: $\quad 1.015$

Median: $\quad 0.538$

Max. $\quad 8.983$

Min. 1.37E-07

Std. $\quad 1.308$

Skewness: $\quad 2.307$

Kurtosis: $\quad 9.853$

Full Sample

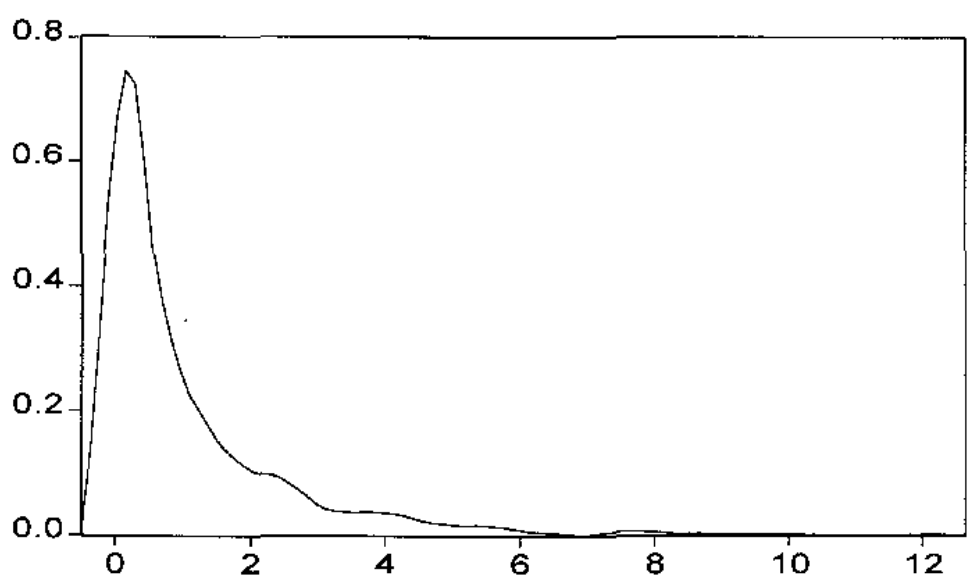

Mean: $\quad 1.044$

Median: $\quad 0.505$

Max.: $\quad 12.150$

Min.: $\quad 1.95 \mathrm{E}-06$

Std.: $\quad 1.454$

Skewness: 2.689

Kurtosis: 12.914 
Figure 4. Confidence Interval for the Threshold Estimate (5-Year Average)
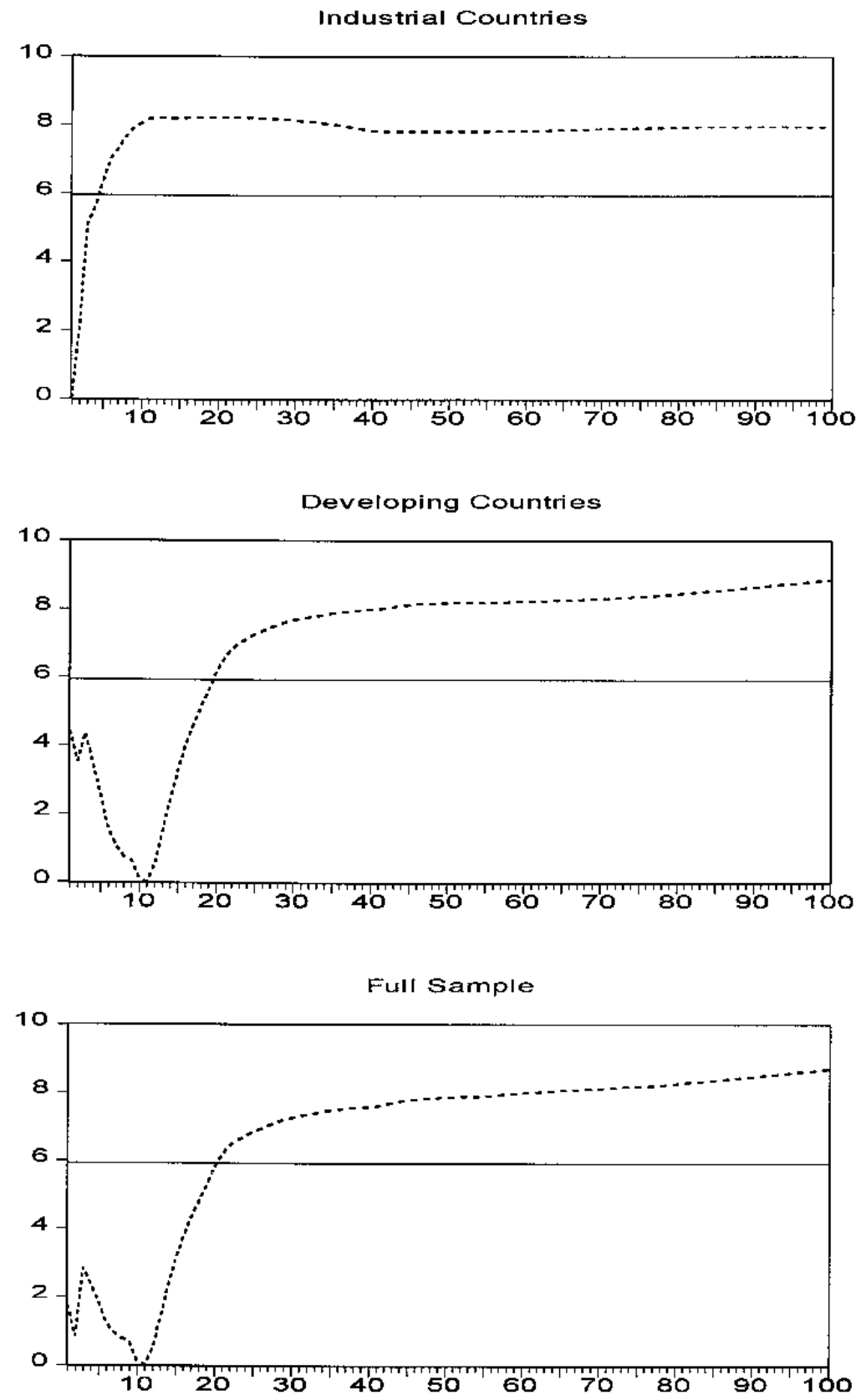

Note: The three panels show the statistic $L R_{i}=\left(S_{0}-S_{l}\right) / \mathrm{s}$.e for breaks occurring at inflation levels from 1 percent to 100 percent (except for industrial countries for which the range is $1-30$ percent), with increments of 1 percentage point, where $S_{0}$ is the sum of square residuals without a break, $S_{I}$ is the sum of square residuals with a break, and s.e. is the standard error of regression. The horizontal line depicts the 10 percent confidence interval. The area below the horizontal forms the no-rejection region. The statistic $L R$, takes a zero value at the optimal threshold. 
Figure 5. Sensitivity of the Effect of Inflation on Growth to the Threshold Level (5-Year Average)
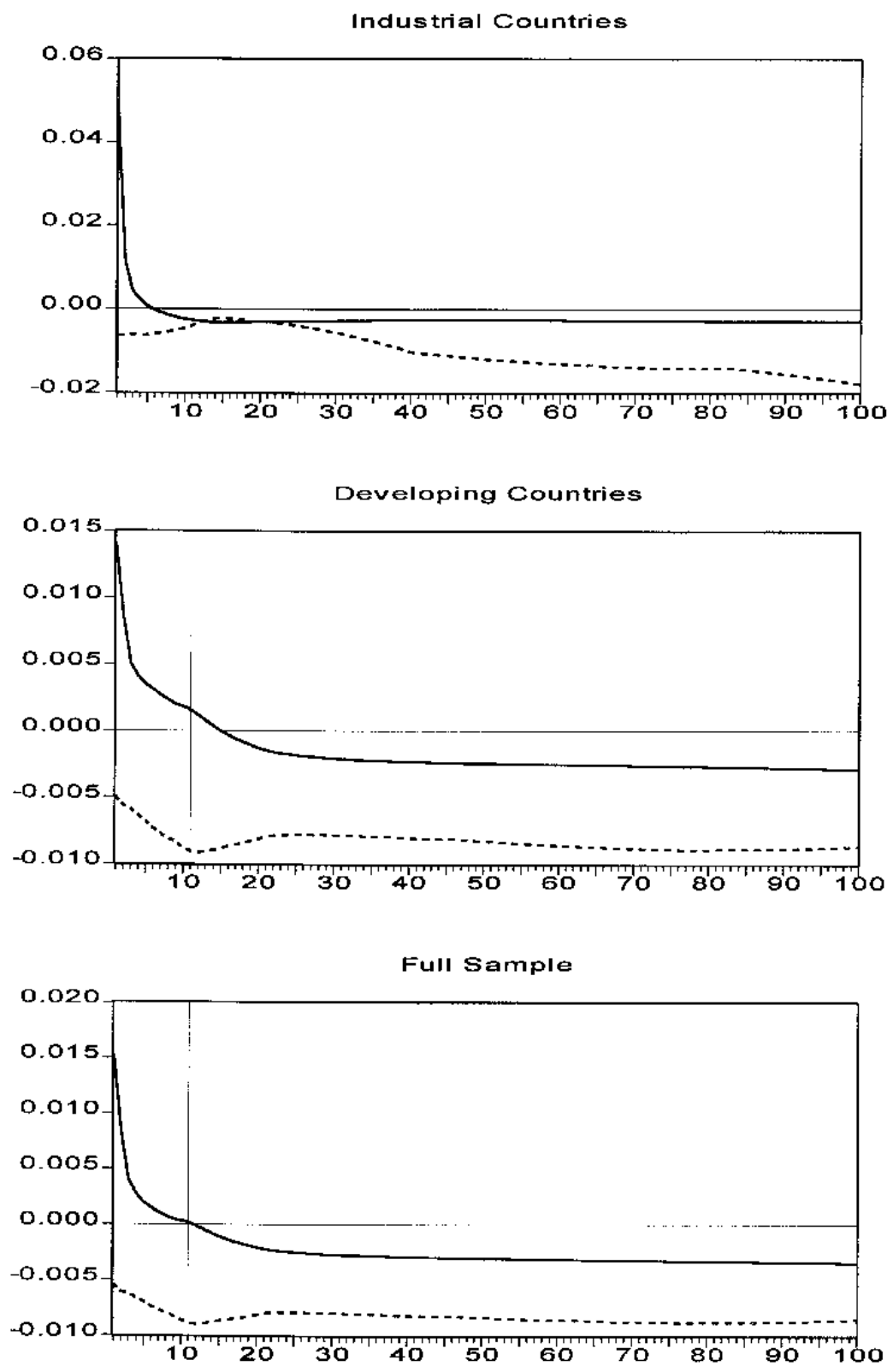

Note: The low (solid line) and high (dotted line) effects are respectively given by the coefficients $\gamma_{1}$ and $\gamma_{1}+\gamma_{2}$ in equation (1). The threshold varies from 1 to 100 percent, except for industrial countries where the range is from 1 to 30 percent. The vertical line indicates the estimate of the inflation threshold. 
Figure 6. Confidence Interval for Threshold Estimate (Yearly Data)
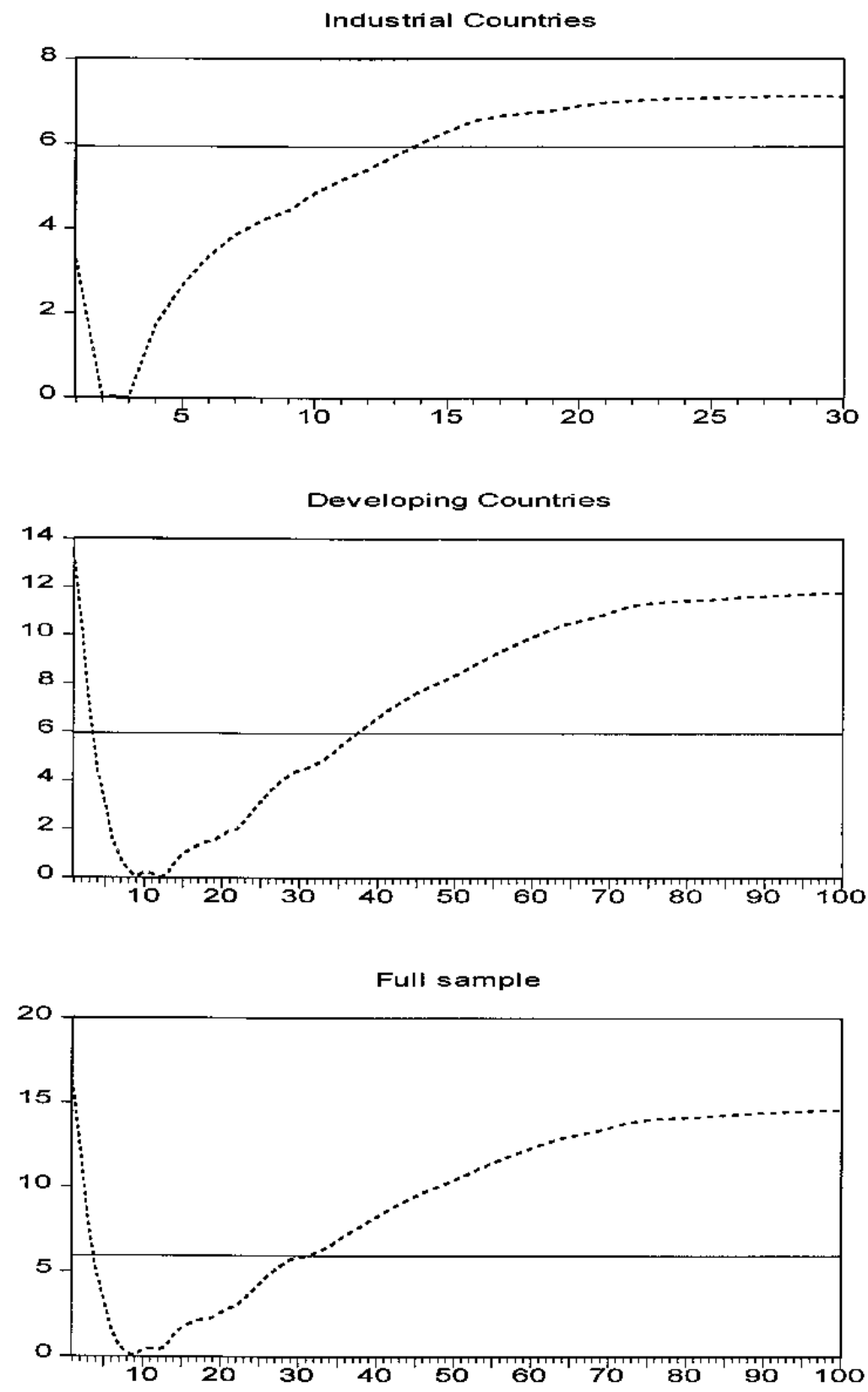

Note: The three panels show the statistic $L R_{l}=\left(S_{0}-S_{l}\right) /$ s.e for breaks occurring at inflation levels from 1 to 100 percent (except for industrial countries for which the range is $1-30$ percent) with increments of 1 percentage point, where $S_{0}$ is the sum of square residuals without a break, $S_{I}$ is the sum of square residuals with a break, and s.e. is the standard error of regression. The horizontal line depicts the 10 percent confidence interval. The area below the horizontal forms the non-rejection region. The statistic $L R_{i}$ takes a zero value at the optimal threshold. 


\section{References}

Ball, Laurence, 1992, "Why Does High Inflation Raise Inflation Uncertainty?" Journal of Monetary Economics, Vol. 29, No. 3, pp. 371-88.

Barro, Robert, 1991, "Economic Growth in a Cross-Section of Countries," Quarterly Journal of Economics," Vol. 106, No. 2, pp. 407-43.

Bruno, Michael and William Easterly, 1998, "Inflation Crises and Long-Run Growth," Journal of Monetary Economics, Vol. 41(February), pp. 3-26.

Bulkley, George, 1984, "Does Inflation Uncertainty Increase with the Level of Inflation?" European Economic Review, Vol. 25, No. 2, pp. 213-21.

Christoffersen, Peter F., and Peter Doyle, 1998, "From Inflation to Growth: Eight Years of Transition," IMF Working Paper 98/99 (Washington: International Monetary Fund).

Cukierman, Alex, Sebastian Edwards, and Guido Tabellini, 1992, "Seigniorage and Political Instability," American Economic Review, Vol. 82, No. 3, 537-55.

De Gregorio, José, 1992, "Effects of Inflation on Economic Growth—Lessons from Latin America," European Economic Review, Vol. 36 (April), pp 417-25.

Easterly, William, 1996, "When Is Stabilization Expansionary?" Economic Policy, Vol. 7 (April), pp. 67-107.

Fischer, Stanley, 1983, "Inflation and Growth," NBER Working Paper No. 1235

(Cambridge, Massachusetts: National Bureau of Economic Research).

— 1993, "The Role of Macroeconomic Factors in Growth," Journal of Monetary Economics, Vol. 32 (December), pp. 485-512.

Fischer, Stanley, Ratna Sahay, and Carlos Vegh, 1997, "Stabilization and Growth in Transition Economies: The Early Experience," Journal of Economic Perspectives, Vol. 10 (Spring), pp. 45-66.

Ghosh, Atish, and Steven Phillips, "Warning: Inflation May Be Harmful to Your Growth," IMF Staff Papers, International Monetary Fund, Vol. 45, No. 4, pp. 672-710.

Grier, Kevin, and Mark Perry, 1996, "Inflation, Inflation Uncertainty, and Relative Price Dispersion: Evidence from Bivariate GARCH-M Models," Journal of Monetary Economics, Vol. 38 (October), pp. 391-405. 
Hadjimichael, Micheal, Daneshwar Ghura, and others, 1995, Sub-Saharan Africa: Growth, Savings, and Investments, 1986-93, IMF Occasional Paper No. 118 (Washington: International Monetary Fund).

Hansen, Bruce, 1996, "Inference When a Nuisance Parameter Is Not Identified Under the Null Hypothesis," Econometrica, Vol. 64 (March), pp. 413-30.

_ 1999, "Threshold Effects in Non-Dynamic Panels: Estimation, Testing, and Inference," Journal of Econometrics, Vol. 93, No. 2, pp. 345-68.

Hansen, Bruce, 2000, "Sample Splitting and Threshold Estimation," Econometrica, forthcoming.

King, Robert, and Ross Levine, 1993, "Finance and Growth: Schumpeter Might Be Right," Quarterly Journal of Economics, Vol. 108 (August), pp. 717-37.

Levine, Ross, and David Renelt ,1992, "A Sensitivity Analysis of Cross-Country Growth Regressions," American Economic Review, Vol. 82 (May), pp. 942-63.

Levine, Ross, and Sara Zervos, 1993, "What We Have Learned About Policy and Growth from Cross-Country Regressions?" American Economic Review Papers and Proceedings, Vol. 83 (May), pp 426-30.

Ma, Henry, 1998, "Inflation, Uncertainty, and Growth in Colombia," IMF Working Paper WP/98/161 (Washington: International Monetary Fund).

Mankiw, Gregory, David, Romer, and David Weil, 1992, "A Contribution to the Empirics of Economic Growth,” Quarterly Journal of Economics, Vol. 107 (May), pp. 407-37.

Roubini, Nouriel, and Xavier Sala-i-Martin, 1995, "A Growth Model of Inflation, Tax Evasion, and Financial Repression,"Journal of Monetary Economics, Vol. 35 (April), $275-301$.

Sala-i-Martin, Xavier, 1997, "I Just Ran Two Million Regressions," American Economic Review, Vol. 87, No. 2, pp. 178-83.

Sarel, Michael, 1996, "Nonlinear Effects of Inflation on Economic Growth," IMF Staff Papers, International Monetary Fund, Vol. 43 (March), pp. 199-215.

Sbordone, Argia, and Kenneth Kuttner, 1994, "Does Inflation Reduce Productivity?" Economic Perspectives, Vol. 18 (November-December), pp. 2-14. 